\title{
ANALISIS STRATEGI PENGEMBANGAN PERIKANAN RAJUNGAN DI PANTAI PUDING BANGKA SELATAN
}

\author{
DEVELOPMENT STRATEGY ANALYSIS OF SWIMMING CRAB FISHERIES IN PUDING BEACH, SOUTH \\ OF BANGKA
}

\author{
Dewi Rachmadini ${ }^{*}$, Kurniawan ${ }^{1}$, dan Arief Febrianto ${ }^{2}$ \\ ${ }^{1}$ Jurusan Manajemen Sumberdaya Perairan FPBB-UBB Balunijuk \\ ${ }^{2}$ Dinas Provinsi Kelautan dan Perikanan, Bangka Belitung \\ *Email korespondensi: dewirachmadini09@gmail.com
}

Diterima januari; disetujui februari tersediasecara online april

\begin{abstract}
The swimming crab is a type of sea crab whose abudance is distributed almost evenly across Indonesian waters. There are aspect that need to be considered in the use of swimming crab resources, namely biological technical, and economical aspect. So, taht it can be done without endangering the sustainability of the resources. The research was conducted from April through July, 2018, in Puding Beach, South Bangka Regency. The primary and secondary data were obtained using 3 method of analysis, namely analysis of maximum sustainable yield (MSY), analysis of utilization rates, business analysis, and SWOT analysis. The result suggested that the MSY value was of 1,319.059 ton/year and the foptimum was 23,877.356 trips/year. This suggests that overfishing has taken place ang that the utilization of swimming crab resources has surpassed the limit of TAC. the fishing gear used by fisherman for catching swimming carbs in Puding Beach is the collapsible trap with the operating principle of one day fishing. Based on business analysis, it was found that the activity is profitable for the fisherman and tah business if feasible. The researchers also formulated 8 alternative strategies for crab meat business development in Puding Beach.
\end{abstract}

Keyword: Biology, Technical, and Economical Aspect, Development Strategy of Swimming Crab Fisheries.

\section{PENDAHULUAN}

Rajungan merupakan salah satu hasil laut yang banyak dimanfaatkan untuk kebutuhan usaha, terutama bagi masyarakat yang hidup di wilayah pesisir. Ketersediaan rajungan hampir tersebar di seluruh wilayah perairan Indonesia, salah satunya adalah perairan Pantai Puding. Alat penangkapan yang ditujukan untuk menangkap rajungan adalah jenis perangkap (traps) yakni bubu lipat. Penggunaan bubu lipat sangat dimungkinkan untuk menangkap rajungan karena dalam pengoperasiannya rajungan yang menjadi target penangkapan dibiarkan masuk tanpa adanya paksaan. Hal tersebut menyebabkan hasil tangkapan dalam yang kondisi baik, artinya terjadinya kerusakan pada tubuh rajungan sangat kecil kemungkinannya (Karnan, 2012).

Pada kegiatan pemanfaatan sumberdaya rajungan khususnya untuk keperluan usaha terdapat faktor yang harus diperhatikan, diantaranya adalah ketersediaannya sumberdaya rajungan yang dapat dimanfaatkan, kegiatan penangkapan serta aspek ekonomi. Hal ini didasari dengan, bahwa pengelolaan sumberdaya perikanan adalah bagaimana kegiatan pemanfaatan sumberdaya ikan, sehingga memberikan manfaat secara ekonomi yang tinggi namun tetap menjaga kelestarian dari sumberdaya ikan tersebut (Hakim, 2014). Dengan mengetahui kondisi sumberdaya rajungan yang ada di perairan, pemanfaatan rajungan dapat dilakukan dengan baik. Keterbatasannya informasi mengenai stok rajungan yang dapat dimanfaatkan dan kajian mengenai pengembangan perikanan rajungan di Pantai Puding belum pernah dilakukan sebelumnya. Menimbang hal tersebut perlu dilakukannya penelitian terhadap potensi dan pengembangan perikanan rajungan. Tujuan penelitian ini adalah menganalisis kondisi perikanan rajungan di Pantai Puding Bangka Selatan dan menentukan strategi untuk pengembangan perikanan rajungan di Pantai Puding Bangka Selatan.

\section{METODE}

Penelitian ini dilaksanakan pada tahun 2018 di Pantai Puding Kabupaten Bangka Selatan. Peta penelitian dapat dilihat pada Gambar 1. 


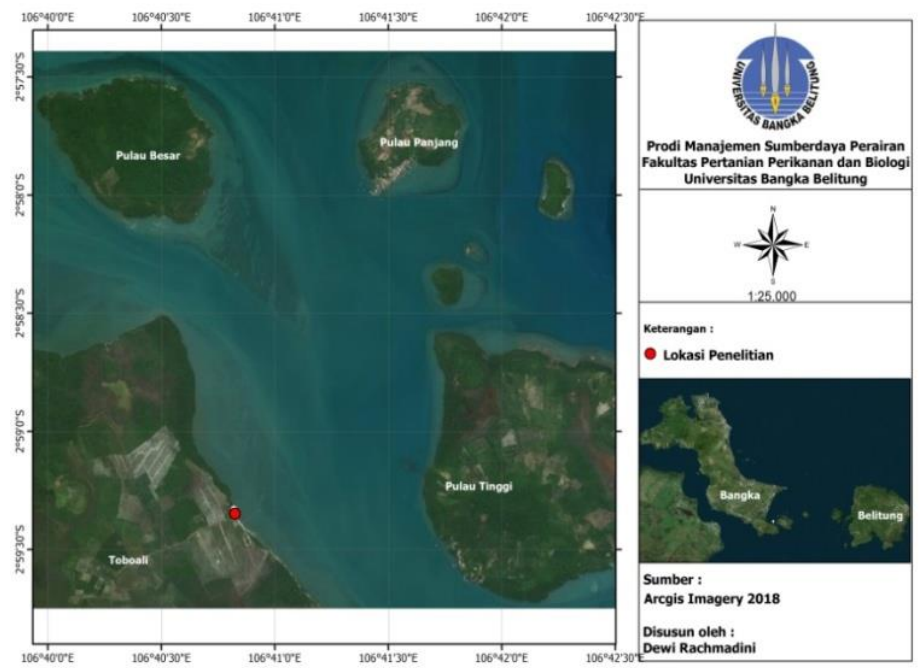

Gambar 1. Peta Lokasi Penelitian

Metode yang digunakan adalah deskriptif kuantitatif. Metode ini dilakukan dengan pengumpulan data yang meliputi data primer dan sekunder. Data primer diperoleh berdasarkan pengukuran, wawancara, serta pengamatan langsung dilapangan dan data sekunder diperoleh dari Dinas Pertanian Pangan dan Perikanan Kabupaten Bangka Selatan.

Metode pengambilan sampel dilakukan secara purposive sampling yakni metode pengambilan responden yang dilakukan secara sengaja namun dengan pertimbangan tertentu (Sugiyono, 2011). Adapun pertimbangannya adalah sebagai berikut:

1. Nelayan yang dijadikan responden adalah nelayan yang menangkap rajungan di perairan Pantai Puding.

2. Nelayan yang dijadikan responden adalah nelayan yang memiliki unit penangkapan ikan bubu lipat.

3. Nelayan yang dijadikan responden adalah nelayan yang memiliki kapal.

Jumlah responden dihitung berdasarkan rumus Arikunto (2013), sehingga diperoleh 18 responden.

$$
\mathrm{n}=\frac{\mathrm{N} \cdot \mathrm{Z}^{2} \cdot 0,25}{\left[\mathrm{~d}^{2}(\mathrm{~N}-1)\right]+\left[\mathrm{Z}^{2} \cdot 0,25\right]}
$$

Keterangan:

$$
\begin{array}{ll}
\mathrm{n} & \text { : Jumlah sampel } \\
\mathrm{N} & \text { : Jumlah populasi } \\
1 & \text { : Konstanta } \\
0,25 & \text { : Konstanta } \\
\mathrm{D} & \text { : Persen kelonggaran (nilai e: } 10 \%) \\
\mathrm{Z} & \text { : Tingkat kebenaran } 90 \%(1,29)
\end{array}
$$

Analisis data pada penelitian ini berdasarkan aspek biologi, teknis, dan ekonomi yakni analisis potensi maksimum lestari, analisis finansial, dan analisis SWOT. Analisis potensi maksimum lestari dilakukan dengan menghitung data produksi rajungan. Analisis finansial meliputi pendapatan, keuntungan, dan waktu balik modal. Hal tersebut dilakukan untuk mengukur kelayakan dari usaha rajungan dan analisis SWOT dilakukan untuk memperoleh strategi yang paling tepat untuk pengembangan perikanan rajungan.

\section{Aspek Biologi}

Analisis ini dilakukan untuk memperoleh nilai MSY (Maximum Suistable Yield), Total Allowed Catch (TAC), dan Tingkat Pemanfaatan (TP).

\section{Maximum Suistable Yield (MSY)}

Analisis ini dilakukan dengan menggunakan model Schaefer. Adapun rumus yang digunakan adalah sebagai berikut (Sparre and Venema,1999):

$$
\mathrm{MSY}=\frac{1}{b} \exp (\mathrm{a}-1) \text { dan } \mathrm{fMSY}=\frac{1}{b}
$$

Keterangan :

a : Intercept atau gari

b : Slope atau kemiringan

MSY : Hasil tangkapan maksimum lestari

fMSY : Jumlah upaya penangkapan optimal untuk mencapai MSY

\section{Total Allowed Catch (TAC)}

Analisis ini digunakan untuk menghitung berapa banyak potensi sumberdaya rajungan yang boleh dimanfaatkan atau ditangkap. Rumus yang digunakan adalah: (Sparre and Venema, 1999)

$$
\mathrm{TAC}=\frac{80}{100} \times \mathrm{MSY}
$$

Keterangan:

TAC : Jumlah rajungan yang boleh ditangkap

MSY : Potensi maksimum lestari dari sumberdaya rajungan

\section{Tingkat Pemanfaatan (TP)}

Tingkat pemanfaatan adalah persentase sumberdaya ikan yang telah dimanfaatan dihitung pertahun. Nilai persentase sumberdaya ikan yang telah dimanfaatkan dapat diketahui dengan rumus sebagai berikut: (Sparre and Venema, 1999). 


$$
\mathrm{T}=\frac{\text { Catch }}{T A C} \times 100 \%
$$

Keterangan:

Catch : Hasil tangkapan tahun ke-i

TAC : Total allowable catch, $80 \%$ dari nilai MSY

$\mathrm{T}$ : Tingkat pemanfaatan

\section{Aspek Teknis}

Teknis dari perikanan rajungan di analisis secara deskriptif berdasarkan pengukuran, wawancara, serta pengamatan langsung dilapangan terkait hal-hal yang berhubungan aspek teknis.

\section{Aspek Ekonomi}

Analisis finansial berfungsi untuk mengetahui tingkat pendapatan dari nelayan dan keberhasilan dari usaha perikanan rajungan yang telah dijalankan selama 1 (satu) tahun. Analisis usaha yang dilakukan bertujuan untuk menganalisis usaha perikanan. Analisis usaha akan dilakukan dengan cara menghitung dan mentabulasi data yang diperoleh dari data primer hasil kuisioner.

\section{Keuntungan}

Analisis ini digunakan untuk mengetahui seberapa besar pendapatan yang didapatkan nelayan setelah menjalankan usahanya selama satu musim dalam satu tahun. Rumus yang digunakan (Umar, 2003):

$$
\pi=\mathrm{TR}-\mathrm{TC}
$$

Keterangan:

$\begin{array}{ll}\Pi & \text { : Keuntungan (pendapatan bersih) } \\ \text { TR } & \text { : Total Revenue (penerimaan) } \\ \text { TC } & \text { : Total Cost (biaya total) }\end{array}$

Kriteria:

Jika $\pi$ bernilai positif $(+)$, berarti usaha tersebut mendapatkan keuntungan.

Jika $\pi$ bernilai negatif (-), berarti usaha tersebut mengalami kerugian.

\section{Imbangan Penerimaan dan Biaya}

Analisis ini akan digunakan untuk mengetahui berapa penerimaan yang dihasilkan dalam setiap satu rupiah biaya yang dikeluarkan dari usaha penangkapan ikan selama satu musim dalam satu tahun. Rumus R/C yang digunakan adalah sebagai berikut (Umar, 2003):

$$
\mathrm{R} / \mathrm{C}=\frac{T R}{T C}
$$

Keterangan:

$\mathrm{R} / \mathrm{C}$ : Imbangan penerimaan dan biaya

TR : Total penerimaan (total revenue)

TC : Total biaya (total cost)

Kriteria:

Jika $\mathrm{R} / \mathrm{C}>1$, maka usaha yang dijalankan tersebut mendapatkan untung.

Jika $\mathrm{R} / \mathrm{C}=1$, maka usaha yang dijalankan tersebut tidak untung.
Jika $\mathrm{R} / \mathrm{C}<1$, maka usaha yang dijalankan tersebut mengalami kerugian.

\section{Waktu Balik Modal}

Analisis ini digunakan untuk mengetahui berapa lama waktu yang diperlukan untuk menutupi biaya investasi. Rumus yang akan digunakan untuk analisis ini (Umar, 2007):

$$
\mathrm{PP}=\frac{I}{\pi} \times 1 \text { Tahun }
$$

Keterangan:

PP : Waktu balik modal (payback period)

I : Besarnya biaya sarana dan prasarana

$\pi \quad$ : Keuntungan yang diperoleh dalam satu tahun

\section{Kriteria:}

Jika waktu balik modal lebih pendek waktunya dari maksimum waktu balik modal maka usaha tersebut dapat dikatakan layak untuk dilanjutkan.

Jika waktu balik modal lebih panjang waktunya dari maksimum waktu balik modal maka usaha tersebut dapat dikatakan tidak layak untuk dilanjutkan.

\section{Analisis SWOT}

Analisis Strength, Weakness, Opportunity, dan Threat (SWOT) yang dilakukan dalam penelitian ini bertujuan untuk menentukan strategi dalam pengembangan perikanan rajungan dengan menggunakan data biologi, teknis, dan ekonomi. Penelitian ini menggunakan perumusan strategi evaluasi internal (Internal Factor Evaluation-IFE) dan faktor eksternal (External Factor EvaluationEFE). Pada matriks IFE berkaitan dengan faktor kekuatan dan kelemahan yang dianggap penting. Sedangkan matrik EFE disusun daftar peluang yang dapat dimanfaatkan dan ancaman yang harus dihindari.

\section{HASIL DAN PEMBAHASAN \\ Potensi Maksimum Lestari (MSY)}

Perhitungan ini menggunakan data produksi time series. Data produksi tersebut berisikan data-data sumberdaya rajungan yang telah dimanfaatkan (ditangkap) selama lima tahun yakni dari tahun 20122016 (Gambar 2)

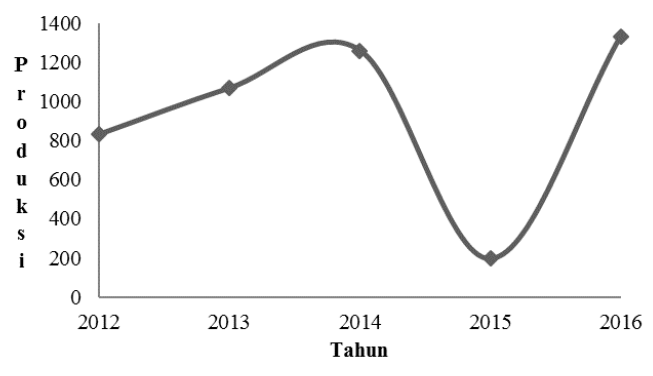


Gambar 2. Produksi Rajungan dari tahun 2012-2016 (Sumber: Dinas Pertanian Pangan dan Perikanan, 2018)

Data diatas menunjukkan bahwa hasil tangkapan rajungan mengalami fluktuasi peningkatan dan penurunan. Produksi rajungan mengalami peningkatan drastis pada tahun 2016 dengan jumlah produksi sebesar 1.330 ton dan terjadi penurunan drastis pada tahun 2015 yakni sebesar 196,5 ton. Total produksi rajungan pada tahun 2012 sampai dengan 2016 adalah 4.686,9 ton dengan rata-rata sebesar 937,38 ton/tahun. Menurunnya jumlah produksi rajungan pada tahun 2015 disebabkan oleh faktor cuaca sehingga nelayan tidak bisa melakukan kegiatan penangkapan secara optimal, oleh karena itu hasil tangkapan yang diperoleh hanya sedikit. Sulistiyawati (2011) yang berpendapat bahwa fluktuasi hasil tangkapan terjadi dikarenakan oleh faktor lingkungan. Hal ini juga sesuai dengan pernyataan Adam (2012) yang menyebutkan bahwa meningkat dan menurunnya jumlah produksi rajungan dapat disebabkan oleh beberapa faktor misalnya musim, ketersediaan stok rajungan di perairan, atau jumlah trip dan waktu nelayan pergi melaut yang sedikit dan tidak lama.

Data produksi rajungan yang telah di analisis menggunakan model surplus dengan metode Schaefer diperoleh hasil sebagi berikut Tabel 1.

Tabel diatas menunjukkan besarnya nilai potensi maksimum lestari rajungan adalah sebesar 1.319,059 ton/tahun dengan f optimum 23.877,356 trip/tahun. Nilai TAC sebesar $1.055,247$ ton/tahun. Tingkat pemanfaatan rajungan pada tahun 2012 masuk ke dalam kategori optimum (66,6\%-99,9\%). Pada tahun 2013, 2014 dan 2016 masuk kategori berlebih $(\geq 100 \%)$. Tahun 2015 masuk ke dalam kategori rendah (0-33,3\%). Rata-rata pemanfaatan rajungan di Bangka Selatan masuk ke dalam kategori optimum. Pada kondisi optimum peningkatan upaya penangkapan masih bisa dilakukan namun dapat membahayakan kondisi daripada sumberdaya rajungan yang masih ada.Kondisi pemanfaatan sumberdaya yang sudah pada tingkat berlebih apabila upaya penangkapan ditambah maka akan membahayakan sumberdaya rajungan dan bahkan akan menyebabkan punahnya sumberdaya di perairan Karnan (2012).

\section{Aspek Teknis}

\section{Unit Penangkapan Rajungan}

Perahu yang digunakan adalah jenis perahu tempel yang terbuat dari kayu. Perahu ini hanya dilengkapi dengan atap yang terbuat dari plastik yang dilipat pada tiang-tiang kayu pada perahu. Panjang kapal \pm 2 meter. Alat penangkapan bubu lipat yang digunakan oleh nelayan di Pantai Puding berbentuk persegi panjang dengan kontruksi rangka yang terbuat dari besi. Iskandar (2012) bahwa alasan nelayan menggunakan bubu lipat untuk melakukan penangkapan ikan dikarenakan alat penangkapan ikan bubu lipat mudah dioperasikan, bisa dilipat sehingga mudah untuk dibawa di kapal dengan jumlah yang banyak dan harga relatif murah dibandingkan dengan jenis alat penangkapan ikan lainnya.

Umpan yang digunakan nelayan umumnya adalah jenis ikan rucah yakni ikan pepetek. Kontruksi dari alat penangkapan bubu lipat dapat di lihat pada Tabel 2.

\section{Metode Pengoperasian Bubu}

Operasi penangkapan rajungan terdiri dari 3 (tiga) tahapan yakni: tahap persiapan, pencarian daerah penangkapan (fishing ground) dan pengoperasian alat tangkap. Metode pengoperasian bubu lipat terdiri dari proses setting, immersing, dan hauling. Hal tersebut juga dibenarkan bahwa pengoperasian alat penangkapan bubu lipat terdiri dari beberapa tahapan yakni, persiapan, (setting), perendaman (immersing), dan pengangkatan (hauling) (Perdana $d k k, 2016$ ). Persiapan ini meliputi pemeriksaan perahu dan alat tangkap, pengisian solar, dan persiapan bubu lipat. Kemudian nelayan berangkat menuju daerah penangkapan. Penentuan titik penurunan bubu umumnya berdasarkan insting atau kebiasaan nelayan. Apabila titik penangkapan sudah ditentukan nelayan segera memasukkan umpan dan menurunkan alat penangkapan bubu lipat ke perairan. Setelah semua bubu diturunkan bubu dibiarkan terendam lalu nelayan kembali ke fishing base. pengangkatan bubu dilakukan setelahnya.

Tabel 1. Hasil Analisis Potensi Maksimum Lestari

\begin{tabular}{clrr}
\hline No. & \multicolumn{1}{c}{ Nilai } & Tahun & Hasil \\
\hline 1. & Intersept (a) & & 0,111 \\
2. & Slope (b) & & $-2,314$ \\
3. & MSY (ton) & & 1319,059 \\
4. & f Optimum & & 23877,356 \\
5. & TAC & & 1055,247 \\
6. & Tingkat Pemanfaatan (\%) & 2012 & 78,854 \\
& & 2013 & 101,237 \\
& & 2014 & 119,403 \\
& & 2015 & 18,621 \\
& 2016 & 126,037 \\
\hline
\end{tabular}


Sumber: Hasil Penelitian, 2018.

Tabel 2. Pengamatan Spesifikasi Alat Penangkapan Bubu Lipat di Pantai Puding

\begin{tabular}{|c|c|c|c|c|c|c|}
\hline \multirow[b]{2}{*}{ No. } & \multirow[b]{2}{*}{ Nama Bagian } & \multirow[b]{2}{*}{ Bahan } & \multicolumn{3}{|c|}{ Ukuran $(\mathrm{cm})$} & \multirow[b]{2}{*}{ Mesh Size } \\
\hline & & & $\mathrm{P}$ & $\ell$ & $\mathrm{T}$ & \\
\hline 1. & Kerangka Bubu & Besi & 47 & 30 & 19 & 2,7 \\
\hline 2. & Jaring & PE & & & & \\
\hline 3. & Tali Utama & $\mathrm{PE}$ & 3000 & & & \\
\hline 4. & Tali Cabang & $\mathrm{PE}$ & 100 & & & \\
\hline 5. & Mulut Bubu & & 11 & 28 & 1,5 & \\
\hline 6. & Pelampung & Sterefoam & 30 & 23 & 18 & \\
\hline
\end{tabular}

\section{Waktu dan Daerah Penangkapan}

Daerah penangkapan rajungan adalah di sekitar Pulau Tinggi dan Pulau Panjang yang letaknya tepat di depan perairan Pantai Puding, dengan jarak operasi yang tidak jauh yakni disekitar perairan Pantai Puding dengan jarak 3 sampai 5 mil. Operasi penangkapan rajungan yang dilakukan nelayan termasuk ke dalam jenis one day fishing atau melaut dalam waktu satu hari. Biasanya nelayan memasang bubu lipat pada sore hari pukul 17.00 kemudian mengangkat bubu pada pagi harinya setelah subuh sekitar pukul 06.00. Namun, ada juga nelayan yang memasang bubu lipat pada pagi hari dan mengangkatnya pada sore hari dengan waktu perjalanan ke daerah penangkapan tidak lebih dari 15 menit.

\section{Musim Penangkapan}

Musim penangkapan rajungan terbagi menjadi 3 (tiga) kategori yakni musim puncak dimana nelayan banyak memperoleh hasil tangkapan, musim biasa dimana tangkapan nelayan adalah sedang, dan paceklik dimana hasil tangkapan nelayan sangat sedikit namun harga jual rajungan tinggi. Berdasarkan wawancara dengan nelayan diperoleh hasil bahwa musim puncak terjadi pada bulan Maret-Juli, biasa Agustus-November, dan musim paceklik terjadi pada bulan Desember-Februari. Pada saat pengambilan data di lapangan rajungan sedang dalam kondisi musim puncak.

\section{Operasional Perikanan Rajungan}

Rajungan yang dijual nelayan adalah bentuk olahan daging yang sudah direbus. Rajungan langsung diproses setelah nelayan sampai di rumah, dimulai dengan mencuci rajungan. Setelah rajungan dicuci bersih, rajungan direbus di dalam panci yang sudah diisi dengan air. Proses perebusan ini masih berlangsung $\pm 10-15$ menit. Apabila rajungan sudah matang, rajungan ditiriskan dan dibiarkan dingin terlebih dahulu. Setelah dingin rajungan dikupas untuk memisahkan daging dari cangkang. Untuk pengumpulan daging rajungan pada saat pengelupasan dipisah antara bagian yang satu dengan yang lainnya. Kemudian dilakukan penimbangan pada daging rajungan yang sudah dikupas dan langsung dikemas ke dalam kap plastik. Terakhir rajungan dijual kepada pengumpul daging rajungan.

\section{Pemasaran}

Produk rajungan yang dijual oleh nelayan di Pantai Puding adalah daging rajungan. Harga daging rajungan dijual seharga Rp. 210.000,00/kg. Harga tersebut ditetapkan sendiri oleh tengkulak (pengumpul daging rajungan). Selain itu harga rajungan ini tidak tetap karena dipengaruhi oleh musim penangkapan. Saluran distribusi daging rajungan merupakan saluran sederhana yakni rajungan yang sudah diolah menjadi daging dijual ke tengkulak (pengumpul daging rajungan). Kemudian berdasarkan wawancara dengan nelayan, setelah daging rajungan tersebut diperoleh, tengkulak langsung mengirimnya ke PT. Dari perusahaan biasanya daging rajungan dikemas lagi dan langsung di ekspor keluar negeri Gambar 3

\section{Aspek Ekonomi}

Aspek ekonomi yang dilihat dalam usaha perikanan rajungan di Pantai Puding adalah bagaimana keadaan dari usaha yang telah dijalankan oleh nelayan, apakah usaha tersebut menguntungkan atau tidak sehingga dapat dikatakan sebuah usaha yang layak atau tidak layak untuk dilanjutkan. Hasil analisis usaha tersebut terdiri dari biaya investasi, biaya tetap, biaya tidak tetap, penerimaan, keuntungan, imbangan penerimaan, dan waktu balik modal.

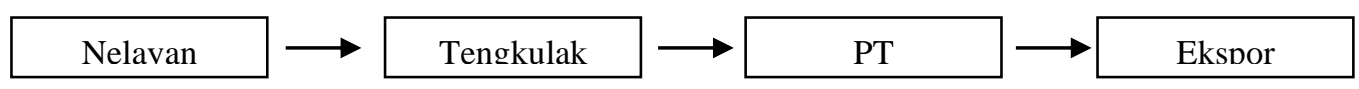

Gambar 3. Saluran Distribusi Rajungan

\section{Biaya Investasi}

Biaya investasi adalah biaya yang pertama kali dikeluarkan oleh nelayan sebelum menjalankan usaha perikanan rajungan. Komponen yang 
termasuk ke dalam biaya investasi adalah alat-alat yang akan digunakan pertama kali untuk menjalankan sebuah usahaseperti perahu, bubu lipat, mesin, ember plastik, kompos gas, dan alat pendukung lainnya. Biaya investasi maksimum dan minimum terdapat pada Tabel 3.

Tabel 3. Rincian biaya investasi

\begin{tabular}{lr}
\hline \multicolumn{1}{c}{ Total biaya investasi } & \multicolumn{1}{c}{ Nilai $(\mathrm{Rp})$} \\
\hline Minimum & $9.040 .000,00$ \\
Maksimum & $10.740 .000,00$ \\
Total rata-rata & $9.679 .444,00$ \\
\hline
\end{tabular}

Sumber: Hasil penelitian, 2018.

Berdasarkan tabel diatas dapat diketahui bahwa untuk memulai usaha perikanan rajungan dibutuhkan biaya investasi minimum sebesar Rp.9.040.000 dan maksimum Rp.10.740.000 dengan rata-rata modal sebesar Rp.9.679.444. dalam suatu usaha perikanan rajungan investasi merupakan komponen penting untuk kelancaran usaha yang bertujuan untuk mendapatkan keuntungan optimal. Menurut Pratama (2012), suatu usaha pasti membutuhkan modal awal untuk memulai usaha tersebut. Besar kecilnya modal tergantung dari jenis usaha yang akan dijalankan. Modal dapat dikatakan berhasil apabila dapat memberikan keuntungan secara ekonomis bagi pengusahanya.

\section{Biaya Produksi}

Biaya produksi merupakan komponen yang harus dikeluarkan untuk menjalankan usaha. Biaya dibagi menjadi dua yaitu biaya tetap dan biaya tidak tetap. Biaya tetap merupakan biaya yang jumlahnya tetap, tidak tergantung kepada perubahan tingkat kegiatan dalam menghasilkan keluaran atau produk. Biaya tidak tetap merupakan biaya yang jumlahnya berubah-ubah sesuai dengan perubahan tingkat produksi. Biaya tidak tetap merupakan biaya yang dikeluarkan untuk proses operasional. Biaya tidak tetap pada usaha rajungan terdiri dari BBM, umpan, gas, dan alat pengemas daging rajungan. Total biaya dapat dilihat pada Tabel 4.

Berdasarkan tabel diatas dapat diketahui bahwa biaya tidak tetap lebih besar dibandingkan biaya tetap. Hal ini dikarenakan biaya tidak tetap selalu dikeluarkan pada setiap trip, dalam usaha perikanan rajungan adalah biaya operasional. Biaya total minimum adalah sebesar Rp. 13.429 .800 dan maksimum Rp. 17.953.000. Biaya total rata-rata dari usaha perikanan rajungan adalah Rp. 16.759.377,78.

\section{Penerimaan}

Penerimaan adalah nilai hasil dari penjualan rajungan per tahun. Penerimaan diperoleh dari perhitungan daging $(\mathrm{kg})$ dikalikan dengan harga jual rajungan (Rp). Penerimaan dalam usaha perikanan rajungan dipengaruhi oleh hasil tangkapan, semakin banyak hasil tangkapan rajungan maka akan semakin banyak penerimaan yang diperoleh oleh nelayan.

Berdasarkan tabel diatas diketahui bahwa penerimaan minimum rajungan per tahun adalah Rp.26.250.000 dan maksimum Rp.32.340.000 dengan total rata-rata sebesar Rp.30.671.666,67. Adapun hasil analisis usaha dapat dilihat pada Tabel 6.

Keuntungan bersih diperoleh dari perhitungan penerimaan dikurangi dengan biaya total dari usaha perikanan rajungan. Selain itu dengan mengetahui keuntungan, nelayan juga dapat mengetahui berapa lama waktu yang akan digunakan untuk pengembalian modal awal. Berdasarkan tabel diatas, keuntungan rata-rata yang diperoleh oleh nelayan rajungan di Pantai Puding per tahun adalah Rp.13.940.788,89. Nilai imbangan penerimaan sebesar 1,830 , dan waktu pengembalian modal rata-rata adalah sekitar 7 bulan. Berdasarkan perhitungan analisis finansial diketahui bahwa penerimaan yang diperoleh lebih besar dari biaya total sehingga usaha perikanan rajungan memperoleh keuntungan. Analisis imbangan penerimaan atau sering disebut dengan Revenue Cost R/C rasio bertujuan untuk mengetahui persentase keuntungan dari biaya produksi yang diperoleh nelayan dalam menjalankan usaha (Rahmi, 2013). Berdasarkan perhitungan diperoleh nilai R/C sebesar 1,830. Menurut Jayantoet al (2013) apabila nilai $\mathrm{R} / \mathrm{C}>1$ maka usaha penangkapan memberikan untung sehingga layak untuk dilanjutkan. Artinya usaha perikanan rajungan di Pantai Puding memberikan keuntungan dan layak untuk dijalankan nelayan. Analisis payback period digunakan agar mengetahui berapa lama waktu yang diperlukan oleh nelayan untuk mengembalikan modal awal dalam usaha perikanan rajungan. Waktu pengembalian modal diperoleh 0,696 yang artinya waktu yang diperlukan nelayan untuk mengembalikan modal awal adalah sekitar 8 bulan. Hal ini menunjukkan bahwa waktu pengembalian modal dalam usaha perikanan rajungan di Pantai Puding dikategorikan cepat karena kurang dari 3 tahun (Setiawan, 2013).

Tabel 4. Biaya Total Usaha Perikanan Rajungan

\begin{tabular}{cllll}
\hline No & \multicolumn{1}{c}{ Uraian Biaya } & \multicolumn{1}{c}{ Minimum } & \multicolumn{1}{c}{ Maksimum } & \multicolumn{1}{c}{ Rata-rata } \\
\hline 1. & Biaya Tetap & Rp.2.529.800 & Rp.3.235.000 & Rp.2.936.488,889 \\
2. & Biaya Tidak Tetap & Rp.10.900.000 & Rp.14.718.000 & Rp.13.822.888,89 \\
\hline & Total biaya & Rp.13.429.800 & Rp.17.953.000 & Rp.16.759.377,78 \\
\hline
\end{tabular}

Sumber: Hasil Penelitian, 2018. 
Tabel 5. Penerimaan Usaha Perikanan Rajungan

\begin{tabular}{ccccc}
\hline No & \multicolumn{1}{c}{ Penerimaan } & Minimum & Maksimum & Rata-rata \\
\hline 1. & Rajungan & Rp.26.250.000 & Rp.32.340.000 & Rp.30.671.666,67 \\
\hline & Total penerimaan & & & Rp.30.671.666,67 \\
\hline
\end{tabular}

Sumber: Hasil Penelitian, 2018.

Tabel 6. Keuntungan, Imbangan Penerimaan, dan Waktu Balik Modal Usaha Perikanan Rajungan

\begin{tabular}{clr} 
No & \multicolumn{1}{c}{ Analisis Usaha } & \multicolumn{2}{c}{ Hasil } \\
\hline 1. & Keuntungan & Rp.13.940.788,89 \\
2. & Imbangan penerimaan dan biaya & 1,830 \\
3. & Waktu balik modal & 0,705 \\
\hline
\end{tabular}

Sumber: Hasil Penelitian, 2018.

\section{Strategi Pengembangan Perikanan Rajungan}

Strategi pengembangan yang dilakukan pada perikanan rajungan di Pantai Puding dilakukan dengan mengidentifikasi faktor internal dan eksternal dan menganalisis berdasarkan IFAS ( Internal Strategic Faktors Analysis Summary) dan EFAS (Eksternal Strategic Faktors Analysis
Summary) untuk menentukan faktor-faktor strategis Tabel 7-8:

Total skor faktor kekuatan adalah sebesar 1,35 dan kelemahan total nilai 1.25. Jumlah nilai secara keseluruhan pada faktor internal (kekuatan dan kelemahan) adalah 2,89. Tabel 7 menunjukkan bahwa nilai faktor kekuatan lebih besar dibandingkan dengan kelemahan.

Tabel 7. IFAS ( Internal Strategic Faktors Analysis Summary)

\begin{tabular}{|l|c|c|c|}
\hline \multirow{2}{*}{ Faktor Internal } & Bobot & \multirow{2}{*}{ Rating } & (Bobot x Rating) \\
\cline { 2 - 2 } - Hasil tangkapan baik & Kekuatan & 3 & 0.45 \\
- Umur nelayan masih produktif & 15 & 2 & 0.2 \\
- Harga jual rajungan tinggi & 20 & 3 & 0.6 \\
- DPI dekat & 5 & 2 & 0.1 \\
\hline Jumlah & $\mathbf{0 . 5}$ & & $\mathbf{1 . 3 5}$ \\
\hline & Kelemahan & 2 & 0.2 \\
\hline - Daya tahan bubu rendah & 10 & 3 & 0.45 \\
- Sarana dan prasarana kurang & 15 & 2 & 0.2 \\
- $\begin{array}{l}\text { Penadai } \\
\text { masih kurang }\end{array}$ & 10 & 3 & 0.3 \\
- Rajungan bersifat musiman & 10 & 2 & 0.1 \\
\hline Umpan terkadang sulit & 5 & & $\mathbf{1 . 2 5}$ \\
\hline Jumlah & $\mathbf{0 . 5}$ & $\mathbf{2 . 6}$ \\
\hline Total & $\mathbf{1 . 0 0}$ & & \\
\hline
\end{tabular}

Sumber: Hasil Penelitian, 2018.

Tabel 8. EFAS (Eksternal Strategic Faktors Analysis Summary)

\begin{tabular}{|l|c|c|c|}
\hline \multicolumn{1}{|c|}{ Faktor Eksternal } & Bobot & \multirow{2}{*}{ Rating } & (Bobot x Rating) \\
\cline { 2 - 3 } & Peluang & 4 & 1 \\
\hline $\begin{array}{l}\text { Permintaan konsumen } \\
\text { terhadap rajungan }\end{array}$ & 25 & 3 & 0.6 \\
\hline Jumlah penduduk tinggi & 20 & & $\mathbf{1 . 6}$ \\
\hline \multicolumn{1}{|c|}{ Jumlah } & $\mathbf{4 5}$ & 1 & 0.2 \\
\hline - Pemaman & 20 & 1 & 0.15 \\
- $\begin{array}{l}\text { Adimum } \\
\text { Adanya pengoperasian trawl }\end{array}$ & 15 & 1 & 0.2 \\
\hline
\end{tabular}




\begin{tabular}{|c|c|c|c|}
\hline Jumlah & 55 & & 0.55 \\
\hline Total & 1.00 & & 2.15 \\
\hline
\end{tabular}

Sumber: Hasil Penelitian, 2018.

Jumlah nilai total peluang adalah 1.6 dan ancaman 0.55. Total skor secara keseluruhan adalah 2.15. Hasil pada tabel 8 menunjukkan peluang lebih besar daripada ancaman.

Tabel 9. Hasil Analisis SWOT

\begin{tabular}{|c|c|c|}
\hline Internal & Kekuatan & Kelemahan \\
\hline Eksternal & $\begin{array}{l}\text { - Hasil tangkapan baik } \\
\text { - Umur nelayan produktif } \\
\text { - Harga jual tinggi } \\
\text { - Daerah penangkapan dekat }\end{array}$ & $\begin{array}{l}\text { - Sarana prasarana } \\
\text { pendukung usaha belum } \\
\text { memadai } \\
\text { - Penanganan hasil tangkapan } \\
\text { kurang } \\
\text { - Rajungan bersifat musiman } \\
\text { - Umpan terkadang sulit }\end{array}$ \\
\hline Peluang & SO & WO \\
\hline 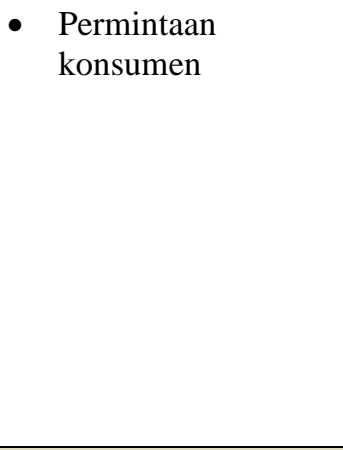 & $\begin{array}{l}\text { - Meningkatkan kualitas nelayan } \\
\left(\mathrm{S}_{2}-\mathrm{S}_{3}-\mathrm{O}_{1}-\mathrm{O}_{2}\right)\end{array}$ & 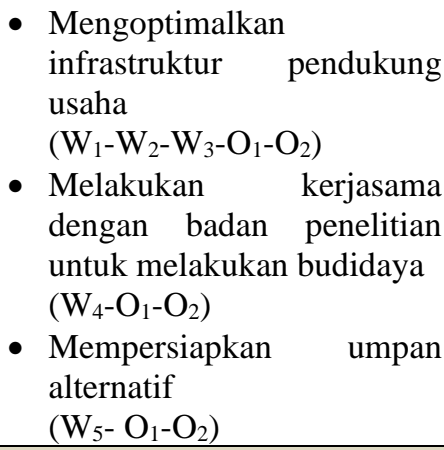 \\
\hline Ancaman & ST & WT \\
\hline $\begin{array}{l}\text { Pemanfaatan } \\
\text { rajungan sudah } \\
\text { optimum }\end{array}$ & $\begin{array}{llr}\text { - } & \text { Melakukan kontrol } & \text { dan } \\
\text { pengawasan pada } & \text { kegiatan } \\
\text { penangkapan rajungan } & \\
\left(\mathrm{S}_{2}-\mathrm{S}_{3}-\mathrm{T}_{1}\right) & \\
\end{array}$ & $\begin{array}{l}\text { - } \text { Melakukan kontrol kegiatan } \\
\text { penangkapan } \\
\left(\mathrm{W} 1-\mathrm{W}_{2}-\mathrm{W}_{3}-\mathrm{T}_{1}-\mathrm{T}_{2}\right)\end{array}$ \\
\hline $\begin{array}{l}\text { - } \begin{array}{l}\text { Bertambahnya } \\
\text { pesaing }\end{array} \\
\text { - Adanya } \\
\text { pengoperasian } \\
\text { trawl }\end{array}$ & $\begin{array}{l}\text { - Meningkatkan kualitas nelayan } \\
\left(\mathrm{S}_{1}-\mathrm{S}_{2}-\mathrm{S}_{3}-\mathrm{T}_{2}\right)\end{array}$ & $\begin{array}{l}\text { - Melakukan } \\
\text { umpan } \\
\left(\mathrm{W}_{2}-\mathrm{T}_{2}\right)\end{array}$ \\
\hline
\end{tabular}

\section{Sumber: Hasil Penelitian, 2018}

Berdasarkan hasil analisis faktor internal dan eksternal pada usaha perikanan rajungan diperoleh 8 (delapan) kemungkinan strategi yang dapat diterapkan.

\section{A. Strategi S-O}

Strategi yang dapat diterapkan dalam menggunakan kekuatan untuk merebut peluang adalah meningkatkan kualitas nelayan dalam mengoptimalkan usaha, dengan cara melakukan penanganan hasil tangkapan dengan baik sesuai dengan SOP (Standar Operation Prosedure) sehingga dapat menjaga kualitas rajungan. Hal ini diharapkan dapat menjaga agar permintaan terhadap hasil olahan rajungan dari nelayan di Pantai Puding tetap ada dan memenuhi kriteria permintaan pasar atau perusahaan terpadu (PT). Strategi ini dapat terwujud apabila adanya pembinaan mengenai tata cara dalam pengolahan daging rajungan dari Pemerintah Kabupaten Bangka Selatan. Selain menangani hasil tangkapan dan pengolahan daging rajungan, nelayan juga dapat diarahkan untuk melakukan pengolahan limbah dari rajungan menjadi sesuatu yang lebih bermanfaat dan ada nilai jualnya. Apabila diterapkan, selain menambah penghasilan bagi nelayan juga dapat mencegah kerusakan lingkungan akibat dari pembuangan limbah. Strategi ini dapat dilakukan dengan cara Pemerintah melakukan kerjasama dengan badan peneliti atau mahasiswa yang ingin melakukan 
penelitian untuk mengolah limbah dari rajungan dan dapat diajarkan kepada nelayan.

\section{B. Strategi W-O}

Strategi yang kemungkinan dapat dilakukan untuk meminimalkan kelemahan untuk merebut peluang yang ada adalah pertama, mengoptimalkan infrastruktur pendukung usaha perikanan rajungan di Pantai Puding, seperti memperbaiki dermaga yang sudah dalam kondisi rusak. Selain menjadi tempat untuk bersandarnya perahu nelayan, dermaga juga mendukung kegiatan penangkapan; menjadi media untuk memudahkan nelayan berjalan menuju perahu dan juga membawa umpan dan hasil tangkapan serta perlengkapan lainnya. Mengadakan tempat pendaratan dan pelaporan hasil tangkapan rajungan terdekat dari Pantai Puding sehingga pemanfaatan rajungan bisa lebih jelas dan terdata.

Sulitnya umpan pada kegiatan perikanan rajungan akan mengganggu proses operasional usaha rajungan yang dijalankan nelayan. Pada kondisi ini strategi yang dapat dilakukan adalah dengan menggunakan umpan alternatif yang efektif dan murah. Hal ini dapat diterapkan dengan cara Kabupaten Bangka Selatan melakukan kerjasama dengan badan peneliti untuk menentukan umpan yang efektif dalam melakukan penangkapan rajungan dengan menggunakan alat tangkap bubu lipat selain ikan pepetek.

Hasil tangkapan rajungan dipengaruhi oleh musim penangkapan. Pada musim puncak hasil tangkapan nelayan akan banyak dan sedikit pada musim paceklik. Dengan permintaan rajungan yang tinggi nelayan akan melakukan penangkapan terusmenerus tanpa memperhatikan kondisi biologi dari rajungan. Strategi yang dapat dilakukan untuk mengatasi permasalahan ini adalah dengan mulai melakukan budidaya rajungan di Pantai Puding, sehingga nelayan tidak selalu bergantung pada hasil tangkapan laut.

C. Strategi S-T

Strategi ini dapat dilakukan dengan menggunakan kekuatan yang ada untuk menghindari ancaman adalah dengan melakukan kontrol dan pengawasan terhadap kegiatan penangkapan rajungan karena berdasarkan analisis data rata-rata pemanfaatan sumberdaya rajungan di Kabupaten Bangka Selatan sudah masuk ke dalam kategori optimum. Misalnya, nelayan melakukan kegiatan penangkapan rajungan pada saat musim puncak saja. Sehingga hasil tangkapan yang diperoleh nelayan banyak dan pada saat musim paceklik tidak dilakukan penangkapan untuk membiarkan sumberdaya rajungan melakukan pemulihan kembali (renewable). Hal ini tentu dapat diterapkan pada usaha rajungan di Pantai Puding apabila pemerintah membuat peraturan pada musim penangkapan dan ukuran rajungan yang boleh di tangkap nelayan.
Meningkatkan kualitas nelayan dengan cara memberikan pengetahuan cara pengoperasian alat tangkap bubu yang benar, waktu penangkapan yang baik untuk rajungan, dan penanganan hasil tangkapan sehingga dapat menghasilkan produk usaha yang berkualitas. Hal ini dapat dilakukan dengan cara Pemerintah melakukan kerjasama dengan penyuluh maupun akademisi di bidang perikanan untuk memberikan pembinaan dan pelatihan bagi nelayan dibawah koordinasi dari pemerintah setempat..

D. Startegi W-T

Strategi yang dapat dilakukan untuk meminimalkan kelemahan dan ancaman adalah dengan melakukan kontrol pada kegiatan penangkapan mulai dari musim penangkapan dan ukuran rajungan yang boleh ditangkap. Sulitnya umpan pada kegiatan perikanan rajungan menjadi kendala yang tidak terselesaikan dari tahun ke tahun dikarenakan antara nelayan rajungan dengan trawl saling membutuhkan. Nelayan rajungan memperoleh umpan berupa ikan pepetek dengan harga yang murah dari nelayan trawl. Apabila nelayan membeli pepetek dari hasil tangkapan alat penangkapan ikan lainnya harganya akan lebih mahal. Berdasarkan wawancara, pernah dilakukan pemberhentian penggunaan alat tangkap trawl di Kabupaten Bangka Selatan, hal tersebut menyebabkan sulitnya nelayan rajungan mendapatkan umpan ikan pepetek. Strategi yang dapat dilakukan untuk mengatasi permasalahan tersebut adalah dengan mengganti umpan yang juga efektif dan murah untuk menangkap rajungan. Adapun semua strategi yang kemungkinan dapat diterapkan untuk pengembangan usaha perikanan rajungan di Pantai Puding dilakukan dengan memperhatikan aspek biologi, teknis, dan juga dari segi ekpnominya. Hal ini didasari bahwa pengelolaan sumberdaya pesisir dan laut yang disusun, hendaknya didasari atau mempertimbangkan empat aspek/dimensipembangunan berkelanjutan, yaitu aspek biologi, aspek teknis, aspek sosial, aspek ekonomi dan keramahan lingkungan (Rosalina, 2011).

\section{SIMPULAN DAN SARAN \\ Simpulan}

Berdasarkan hasil penelitian dapat diambil kesimpulan sebagai berikut:

1. Kondisi perikanan rajungan secara biologi dengan nilai ptensi maksimum lestari sebesar $1.319,059$ ton dengan tingkat pemanfaatan masuk ke dalam kategori optimum. Secara teknis, nelayan di dominasi dengan nelayan tradisional dengan alat tangkap bubu lipat yang menggunakan perahu kapasitas < 3 GT dan daerah penangkapan $<5$ mil dan musim penangkapan puncak pada bulan Maret-Juli. Secara ekonomi biaya investasi usaha perikanan rajungan dengan rata-rata $\mathrm{Rp}$. 9.679.444 dan R/C 
$1,83>\mathrm{R} / \mathrm{C} 1$ sehingga dikategorikan usaha yang memperoleh keuntungan dan layak untuk dilanjutkan.

2. Strategi yang kemungkinan dapat dilakukan pada usaha perikana rajungan di Pantai Puding adalah meningkatkan kualitas nelayan dalam mengoptimalkan usaha, mengoptimalkan infrastruktur pendukung usaha perikanan rajungan, mempersiapkan umpan alternatif, melakukan perencanaan program budidaya rajungan, melakukan kontrol dan pengawasan terhadap kegiatan penangkapan rajungan, dan meningkatkan kualitas nelayan dalam operasional usaha.

\subsection{Saran}

Berdasarkan analisis yang telah dilakukan peniliti ingin memberikan beberapa saran yang diharapkan dapat bermanfaat dan membantu dalam pengembangkan perikanan rajungan di Pantai Puding Kabupaten Bangka Selatan Adapun saran tersebut diantaranya:

1. Pemerintah diharapkan dapat lebih memperhatikan usaha rajungan di Pantai Puding, mulai dari infrastruktur dan jika memungkinkan memberikan bantuan berupa alat pengolahan daging rajungan kepada nelayan agar terjaga kualitas produk.

2. Perlu dilakukannya penelitian lanjutan mengenai umpan alternatif dan upaya melakukan budidaya pada pemanfaatan sumberdaya rajungan untuk kegiatan usaha di Pantai Puding Kabupaten Bangka Selatan.

\section{UCAPAN TERIMA KASIH}

Penulis mengucapkan terima kasih kepada Kurniawan, S.Pi., M.Si dan Dr. Arief Febrianto atas bimbingan dan arahan dalam penyusunan jurnal ini.

\section{DAFTAR PUSTAKA}

Adam, Lukman. 2012. Kebijakan Pengembangan Perikanan Berkelanjutan (Studi Kasus: Kabupaten Wakatobi, Provinsi Sulawesi Tenggara dan Kabupaten Pulau Morotai, Provinsi Maluku Utara. Jurnal Perikanan Vol. II No. 2: 115-126.

Arikunto, Suharsimi. 2013. Prosedur Penelitian : Suatu Pendekatan Praktik. Cetakan Kelimabelas. Jakarta : Rineka Cipta.

Hakim, Lugas L., Anna S., dan Junianto. 2014. Analisis Bioekonomi Sumber Daya Ikan Tenggiri (Scomberomorus Commerson) di Perairan Kabupaten Indramayu Jawa Barat. Kebijakan Sosek KP Vol. 4 No. 2.

Iskandar D. 2012. Daya Tangkap Bubu Lipat Yang Dioperasikan Oleh Nelayan Tradisional Di Desa Mayangan Kabupaten Subang. Jurnal Saintek Perikanan Vol. 8, No. 2: 1-5.

Jayanto, Bagi. B., Bambang, Aziz. N., dan Boesono, H. 2013. Analisis Produksi Dan Keragaan Usaha
Garuk Udang Di Perairan Kota Semarang. Jurnal Sanitek Perikanan Vol. 8 (2): Hlm 57-62.

Karnan. 2012. Model Pengelolaan Perikanan Tangkap di Selat Alas - Nusa Tenggara Barat. Jurnal Pemanfaatan Sumberdaya Perairan Vol. 20(4): 391-401.

Perdana, Mohammad Taubatullah Isyak., Boesono, Herry., dan Sardiyatmo. 2016. Pengaruh Umpan dan Lama Perendaman Alat Tangkap Jebak (Bubu Lipat) Terhadap Hasil Tangkapan Rajungan (Portunus pelagicus) di Desa Semat, Jepara. Journal of Fisheries Resource Utilization Management and Technology Volume 5, Nomor 1, Hlm 1-8.

Pratama, Ficka. A. 2012. Analisis Kelayakan Finansial Usaha Penangkapan Ikan Menggunakan Panah Dan Bubu Dasar Di Periran Karimunjawa. Jurnal Fisheries Resources Utilization Management and Technology. Vol. 1 No. 1: Hlm 22-31.

Rahmi, Tiara. A. 2013. Usaha Perikanan Tangkap Skala Kecil Di Sadeng Provinsi Daerah Istimewa Yogyakarta. Jurnal Amanisal PSP FPIK Unpatti-Ambon. Vol. 2. No.2: 40-45.

Rosalina, D. 2011. Analisis Strategi Pengembangan Perikanan Pelagis Di Kabupaten Banyuasin Provinsi Sumatera Selatan.Jurnal Kebijakan Sosial Ekonomi Kelautan dan Perikanan Vol. 1 No. 1. (2011): 12-15.

Setiawan, Ringga. 2013. Analisis Usaha Perikanan Pada Alat Tangkap Bubu Di Perairan Rawapening Desa Lopait Kecamatan Tuntang Kabupaten Semarang. Jurnal Fisheries Resources Utilization Management and Technology Vol. 2 No. 3: Hlm 131-141.

Sparre, P. \& S. C. Venema. 1999. Introduksi Pengkajian Stok Ikan Tropis. FAO dan Pusat Penelitian dan Pengembangan Perikanan. Jakarta. $436 \mathrm{hlm}$.

Sugiyono, H. 2010. Metode Penelitian Kuantitatif Kualitatif dan R\&D. Alfabeta: Bandung. 334 hlm.

Sulistiyawati E T. 2011. Pengelolaan Sumberdaya Ikan Kurisi (Nemipterus furcosus) Berdasarkan Model Produksi Surplus di Teluk Banten, KabupatenSerang, Provinsi Banten [Skripsi]. Bogor (ID): Institut Pertanian Bogor.

Umar 2007. Studi Kelayakan Bisnis: Teknik Menganalisis Kelayakan Rencana Bisnis secara Komprehensif. Edisi ke-3. Jakarta: Gramedia Pustaka Utama

Umar H. 2003. Studi Kelayakan Bisnis: Teknik Menganalisis Kelayakan Rencana Bisnis secara Komprehensif. Jakarta: Gramedia Pustaka Utama. 488 hal. 